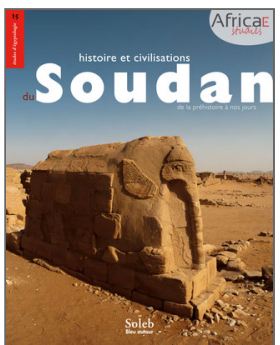

Histoire et civilisation du Soudan

De la préhistoire à nos jours

\title{
Petite bibliothèque subjective
}

DOI : 10.4000/books.africae. 3007

Éditeur : Africae, Soleb, Bleu autour

Lieu d'édition : Paris, Khartoum

Année d'édition : 2017

Date de mise en ligne : 17 janvier 2022

Collection : Africae Studies

EAN électronique : 9782493207074

\section{CpenEdition \\ Books}

http://books.openedition.org

\section{Référence électronique}

Petite bibliothèque subjective In : Histoire et civilisation du Soudan : De la préhistoire à nos jours [en ligne].

Paris, Khartoum : Africae, 2017 (généré le 28 janvier 2022). Disponible sur Internet : <http://

books.openedition.org/africae/3007>. ISBN : 9782493207074. DOI : https://doi.org/10.4000/ books.africae.3007. 
Claude Iverné, Bilad es-Sudan, fondation Henri-Cartier-Bresson, éditions Xavier-Barral, Paris, 2017

Sudan Photographs, vol. 1, 2, 3 et 4, el-Nour, Paris, 2012, 2014, 2016 et 2019

Leila Aboulela, Minaret, éditions Flammarion, hors collection, Paris, 2006

La Traductrice, éditions Zoé, Carouge, Suisse, 2003

Maha Ayoub, Nile Blues, Createspace (https://www.createspace.com/3857425), 2012

Mansour Khalid, Nimeiri and the Revolution of Dismay, Routledge, Londres, 1985

Jamal Mahjoub, Le Train des sables, Actes Sud, collection Lettres africaines, Arles, 2001

Là d'où je viens, Actes Sud, collection Lettres africaines, Arles, 2004

Nubian Indigo, Actes Sud, collection Lettres africaines, Arles, 2006

Olivier Rolin, Méroé, éditions du Seuil, collection Points, Paris, 1998

Port-Soudan, éditions du Seuil, collection Points, Paris, 1994

Tayeb Salih, Saison de la migration vers le Nord, Actes Sud, collection Babel, Arles, 2006

Vivia Amina Yagi, Contes du Soudan, illustrés par Amel Bashir, éditions du Jasmin, Clichy, France, 2015

Marina d'Errico, L'Utopia Tropicale: Khartoum colonia britannica 1898-1910-The Tropical

Utopia: Khartoum British Colony 1898-1910, Terra Ferma, Crocetta del Montello, Italie, 2015

Guillaume Lavallée, Dans le ventre du Soudan, chronique des derniers jours d'un géant,

Mémoire d'encrier, Montréal, Québec, Canada, 2012

Marc Lavergne (sous la direction de), Le Soudan contemporain, de l'invasion turco-égyptienne à la rebellion africaine (1821-1989), Karthala-Cermoc, Paris-Amman, 1989

Michel Raimbaud, Le Soudan dans tous ses états, l'espace soudanais à l'épreuve du temps, Karthala, Paris, 2012

Trésors de l'islam en Afrique, de Tombouctou à Zanzibar, catalogue de l'exposition à l'institut du Monde arabe, Paris, 14 avril-30 juillet 2017, SilvanaEditoriale, Milan, Italie, 2017

Paul Clammer, Sudan, The Bradt Travel Guide, Chalfont Saint-Peter, Bucks, Grande-Bretagne, réimpression 2008

Marc Goutalier, Soudan, 2011-2012, Le Petit futé, nouvelles éditions de l'Université, Paris, 2012

Sudan, South Sudan, carte au 1:1800 000, Reise Know-How, Fernwald, Allemagne, 2013 